\title{
VIDEOBIOGRAFIAS DE EXCLUSÃO NA ESCUTA DE COMPORTAMENTOS DESAFIADORES NA ESCOLA
}

\section{CRISTÓVÃO PEREIRA SOUZA}

Universidade Federal do Rio Grande do Norte

\section{MARIA DA CONCEIÇÃO PASSEGGI}

Universidade Federal do Rio Grande do Norte

RESUMO Discute-se, com base na noção de "educação inclusiva", as dificuldades de aprendizagem e inadaptação escolar de crianças e adolescentes institucionalizados por medida protetiva de abrigo. Pressupõe-se que os significados e sentidos atribuídos por esses indivíduos a suas vivências no tempo/espaço escolar contribuem para a compreensão dos comportamentos desafiadores pelos quais eles são negativamente discriminados, tanto na escola como fora dela. Os preceitos teórico-metodológicos da pesquisa (auto)biográfica e da Antropologia visual apoiaram a produção de narrativas videobiográficas, roteirizadas pelas crianças e adolescentes, como autores, em torno das experiências de vida, antes e durante o acolhimento institucional. Destacam-se aqui, para análise, as narrativas audiovisuais que tomaram a ambiência escolar como contexto para as grafias de si. Os resultados sinalizam a necessidade, na escola, de uma escuta que atente para a riqueza humana e temporal dos trajetos desses meninos e meninas, com sensibilidade às táticas, resistências e valores por eles convocados na arte de viver a singularidade de suas exclusões, marcadas socialmente pela vulnerabilidade e o risco.

Palavras-chave: Pesquisa (Auto)Biográfica. Educação Inclusiva. Formação de Professores. SCHOOL BEHAVIOR MONITORING

Based on the concept of "inclusive education", we discuss learning difficulties and failure to adapt to school in children and adolescents institutionalized through sheltering measures. We assume that meanings and senses through which such individuals configure their experiences in time/school context contribute to our understanding of their challenging behavior, leading to negative discrimination whereas in school or elsewhere. The theoretical and methodologi- 
cal concepts of (auto)biographical research and visual Anthropology supported the production of videobiographical narratives, which were built by their authors according to their life experiences before and during institutionalization. We stress here, for assessment purposes, audiovisual narratives where school context served as a canvass for self-graphs. Results indicate the necessity of school monitoring aimed at the human and time richness of boys and girls paths, and focusing on the techniques, resistance and value they reveal in their way of experiencing exclusion, socially marked by vulnerability and risk.

Keywords: (Auto)Biographical Research. Inclusive Education. Teacher training.

\section{RESUMEN VIDEOBIOGRAFÍAS DE EXCLUSIÓN EN LA ESCUCHA DE COMPORTAMIENTOS ESCOLARES DESAFIANTES}

A partir de la noción de "educación inclusiva", se discuten las dificultades de aprendizaje e inadaptación escolar de niños y adolescentes institucionalizados mediante medida protectora de amparo. Se presupone que los significados y sentidos a través de los cuales tales sujetos configuran sus vivencias en el tiempo y espacio escolar ayudan a comprender los comportamientos desafiantes que hacen que se los discrimine negativamente, ya sea en la escuela como fuera de la misma. Los preceptos teórico-metodológicos de la investigación (auto)biográfica y la Antropología visual apoyaron la producción de narrativas videobiográficas dirigidas por esses niños y adolescentes, sus autores, en relación a las experiencias de vida preescolares y durante la institucionalización. Aquí se destacan para el análisis las narrativas audiovisuales que tomaron el ambiente escolar como contexto para las grafías de sí. Los resultados indican la necesidad escolar de una escucha que atienda la riqueza humana y temporal de los recorridos de esos niños y niñas, destacándose las tácticas, resistencias y valores instrumentados por ellos en el arte de vivir la singularidad de sus exclusiones, marcadas socialmente por la vulnerabilidad y el riesgo.

Palabras clave: Investigación (Auto)Biográfica. Educación Inclusiva. Formación de Profesores.

\section{Introdução}

Este artigo decorre de uma experiência socioeducativa, realizada com a participação de crianças e adolescentes institucionalizados por medida protetiva de abrigo, quando nos foi possivel caminhar uns ao encontro dos outros, em novos reconhecimentos e ressignifica- 
ções de si, mediados pelos pressupostos teórico-metodológicos da pesquisa (auto)biográfica (PASSEGGI, 2008; NÓVOA, 2010; PINEAU; LE GRAND, 2012) e da Antropologia visual (MACHADO, 1997; WOHLGEMUTH, 2005; COMOLLI, 2008; FREIRE; LOURDOU, 2009). O método utilizado, de caráter interdisciplinar, define-se pela configuração de narrativas de vida audiovisuais, produzidas no contexto didático-pedagógico de uma oficina de iniciação à linguagem audiovisual, ministrada no contexto da instituição onde foi realizada a pesquisa, e da qual participaram as crianças e adolescentes abrigados.

De acordo com as determinações acadêmicas, éticas e judiciais, que orientam a investigação científica com crianças e adolescentes, na especificidade da condição de tutelados do Estado, o projeto foi apresentado e aprovado pelo Comitê de Ética em Pesquisa da UFRN, conforme Parecer 050/2012, antes de ingressarmos numa das "Casas de Passagem" de Natal, capital do Rio Grande do Norte, responsável pelo acolhimento de adolescentes na faixa etária entre doze e dezoito anos, assim definidos pelo ECA - Estatuto da Criança e do Adolescente (BRASIL, 1990). Conforme disposições gerais do referido Estatuto, essas instituições acolhem, eventualmente, crianças abaixo de doze anos, para atender ao princípio da inseparabilidade entre grupos de irmãos. Este foi o caso de duas crianças, de nove e dez anos, que colaboraram com este estudo.

Pelo período de seis meses, ingressava conosco no abrigo, três dias por semana, em encontros de quatro a cinco horas, um aparato tecnológico básico, próprio às fases de pré-produção, produção e pós-produção audiovisual: câmeras de vídeo, profissionais e amadoras; microfones; tripés; cabos de conexão; retroprojetor; caixas de som; notebook e demais apetrechos acessórios à produção audiovisual. Essa parafernália era disposta de modo contínuo e sistemático às crianças e aos adolescentes para a realização dos exercícios práticos de iniciação à produção audiovisual. Simultaneamente, como suporte de base ao dispositivo videobiográfico, este estudo, assumiu metodologicamente três fases: iniciação à formação audiovisual; registro audiovisual de narrativas de vida das crianças e adolescentes; debruce reflexivo dos autores sobre as configurações videobiográficas por eles produzidas.

Por um dever deontológico, que orienta os pressupostos éticos do campo da pesquisa (auto)biográfica, a problemática socioeducacional das crianças e adolescentes abrigados vinha apenas, ocasional e pontualmente, se insinuando em nossas inquietações de pesquisa. Para o primeiro autor deste texto, mediante preocupações comunicacionais, através de pautas, matérias e editoriais opinativos, produzidos em torno do tema, ao longo de sua atuação profissional de jornalista, iniciada no ano de 1995. Somente no ano de 2009, a partir do conhecimento pela via jornalística de que estaria em curso um movimento segregacionista de impedimento à instalação do abrigo de adolescentes, na Casa de Passagem III, numa comunidade de classe média alta da capital potiguar, haveria, de nossa parte, um envolvimento definitivo com a temática, agora aliando também as preocupações do educador. Para a segunda autora, tal inquietação pontuava seus projetos de pesquisa, voltados para a legitimação de uma população esquecida pela história e a pesquisa educacional.

A assunção dessa problemática na trajetória do primeiro autor refere-se à emergência da "clareza cidadã", da qual nos fala Freire (2000), quando propõe que não devamos nos afastar da esperança, mesmo diante de fatos dramáticos e de dificil tratamento. Daí que, frente àquela inusitada mobilização comunitária, as nossas predisposições educacionais prontamente nos levaram a realizar uma contabilidade simples. A população do bairro em 
questão ultrapassava os 22 mil moradores (SEMURB, 2008), em princípio pessoas bem-sucedidas e igualmente posicionadas em setores privilegiados e estratégicos do mercado de trabalho e da sociedade em geral. Já o abrigo institucional, objeto da rejeição, abrigava, à época, 32 adolescentes em situação de vulnerabilidade social e risco, e, importante destacar, não infratores, mas vítimas do abandono e da negligência familiar, de abusos e exploração, em variadas dimensões.

O impacto pessoal suscitado por este movimento nos conduziu à decisão de realizar primeiramente um mergulho exploratório na realidade dos abrigos institucionais, a fim de compreender, numa perspectiva socioeducacional, a problemática de uma população, cujo líder comunitário, durante a audiência pública especial que finalmente deliberou na Câmara Municipal pela transferência do abrigo para o bairro, assim se refere: "que eles sejam instalados em qualquer outro bairro, menos aqui" (TELEVISÃO CÂMARA, 2009).

Diante de tamanha animosidade, vaticinamos que, longe de se constituir em um epílogo ideal para os adolescentes, a decisão prenunciava a abertura de um novo capítulo para a rejeição, dando continuidade a uma dramaturgia que certamente elevar-se-ia de intensidade, tão logo se efetivasse a chegada ao bairro daquele indesejável segmento da população de crianças e adolescentes, alçados, radical e prematuramente, à condição aparentemente irreversivel de outsiders (ELIAS; SCOTSON, 2000).

Em meio à antevisão das crianças e dos adolescentes, elevados à condição de forasteiros, por não partilharem dos valores, modos de vida e estatuto econômico daquela comunidade, as preocupações do jornalista dialogam com as predisposições do educador, pertencimento interdisciplinar que nos conduz às formas transitivas e pronominais do verbo formar, que, segundo Nóvoa (2010, p. 22), “é sempre formar-se", dialética que nos instiga à busca de modos pelos quais pudéssemos com esses indivíduos descobrir modos de acompanhá-los rumo à emancipação, através de uma formação que os conduzisse à autonomia, à formulação de projetos pelos quais eles pudessem perspectivar para si modos de vida socialmente inclusivos e produtivos.

Dessa motivação emerge a proposição de uso da tecnologia audiovisual, uma vez que se trata de uma linguagem que oportunizaria acesso indistinto a todos os abrigados que, voluntária e consensualmente, aderissem à colaboração participativa no estudo, independentemente de sua condição escolar, incluindo-se aí aqueles que ainda não haviam ingressado em processos de alfabetização. Assim, dos trinta e dois meninos e meninas acolhidos à época, dezesseis iniciaram o trabalho de colaboração. Desses, onze adolescentes participaram integralmente das atividades, sendo nove na faixa etária entre treze e dezessete anos e dez meses, de ambos os gêneros, além das duas crianças já referidas, ambos do gênero masculino, acolhidos no abrigo para adolescentes, em respeito ao princípio da inseparabilidade dos irmãos, conforme já dissemos em outro momento.

Inicialmente fascinados pelas tecnologias de produção audiovisual, logo os participantes foram igualmente seduzidos pela produção de narrativas videobiográficas, pelas quais passaram a atribuir significados e sentidos a si e aos outros com quem, irmanados pelo compulsório trânsito por aquele contexto institucional, passavam a desenvolver entre si uma consciência socialmente compreensiva daquela realidade. A seguir, mas não sem alguma resistência, eles foram também se deixando sensibilizar tanto pelos exercícios reflexivos em torno das narrativas de vida por eles configuradas em suas videobiografias, quanto pelos debruces em torno dos registros audiovisuais de suas próprias 
condutas na vida cotidiana do abrigo, quando em interação com seus pares de acolhimento e também com seus educadores sociais.

Assim, da profusão de dados decorrentes desse método interdisciplinar, caracterizado privilegiadamente pela abertura, flexibilidade e participação colaborativa, foram selecionadas para este artigo as narrativas pelas quais as crianças e os adolescentes contextualizaram suas produções videobiográficas em torno das experiências escolares. Para além das classificações pontuais pelas quais essa população é categorizada pelo diagnóstico fatalista de que “não se interessavam por nada e que desistiram deles mesmos", prenunciado pela maioria de seus educadores sociais, buscamos compreender, por entre os trajetos perversos e concretos por eles configurados em suas narrativas de vida, os significados, sentidos e valores que atribuem à escola, com destaque para as dificuldades de aprendizagem que os estaciona em sua maioria na condição de analfabetismo.

Frente a uma realidade histórica de perdas multifacetadas, indagamos neste artigo pelos meios educativos e pelas alternativas criativas que possam contribuir para a superação dos obstáculos que se interpõem à escolarização das crianças e adolescentes abrigados, vítimas que são do abandono familiar e comunitário, abusos e explorações, negligência e drogadição. Para além do estigma que os torna vulneráveis à descrença social, o que se busca é conhecerlhes a singularidade dos percursos, focalizando as motivações de suas condutas desafiadoras, com o objetivo de compreender o que eles nos dizem através de seus gestos violentos, indisciplina, indiferença e ironia, pelos quais eles obrigam os seus educadores a enxergá-los.

\section{Fundamentos do estudo}

O processo de construção de uma sociedade democrática, sob os ideários filosóficos do movimento universal dos direitos humanos, pressupõe a construção contínua, sistemática, vigilante e coletiva, de espaços sociais de convívio na diversidade, tornando emergente a cultura de acolhimento às diferenças e, decorrentemente, a problematização das instituições cujas práticas persistam no reforço a todas as formas de discriminação, classificação e hierarquização dos indivíduos, tendo, por base, a especificidade das limitações físicas, mentais e/ou socioculturais que, eventual ou permanentemente, os distingue individual ou coletivamente de uma maioria tradicional ou contingencialmente percebida e referendada socialmente como "normal".

A escola, sendo expressão da cultura na qual se insere e reproduz, e, paradoxalmente, contribui dialeticamente para transformar, assume, nesse contexto de democratização, a missão institucional de promover estratégias educacionais comprometidas com o desenvolvimento de contracondutas à histórica exclusão educacional, buscando a assunção das diferenças enquanto oportunidade de formação cidadã e desenvolvimento humano, indiscriminadamente para todos os formandos. Contudo, sabe-se com Mantoan (2015), que a resistência da escola aos processos de inclusão se estrutura em torno de sua incapacidade de atuar frente à complexidade e à singularidade do que é real nos seres e nos grupos humanos. Nas palavras da autora:

Os alunos não são virtuais, objetos categorizáveis - eles existem de fato, provêm de contextos culturais os mais variados, representam diversos segmentos sociais, produzem e ampliam conhecimentos e têm desejos, aspirações, valores, sentimentos e costumes com os quais se identificam. Em resumo: esses grupos de pessoas não são criações de nossa razão, mas existem em lugares e tempos não ficcionais, evoluem, são compostos de seres encarnados. (MANTOAN, 2015, p. 57) 
Nessa direção, como forma de superação das concepções abstratas das crianças e dos adolescentes, em quaisquer espaços de convívio, a Lei 8.069, de 13 de julho de 1990, mais conhecida como Estatuto da Criança e do Adolescente - ECA (BRASIL, 1990), reconhece aos indivíduos dessas faixas etárias a condição especial de desenvolvimento, e, em decorrência, o direito à proteção integral e ao legítimo lugar de protagonista de sua própria história. Nesses termos, segundo a leitura que faz Souza Neto (2009) do Estatuto, as crianças e os adolescentes flagrados ou submetidos a condutas sociais ditas inadequadas não estariam fora da cultura, mas dela fazendo a sua própria leitura. Segundo o autor (SOUZA NETO, 2009, p. 260), "essa compreensão permite afirmar que a criança e o adolescente são crianças e adolescentes; só são carentes, abandonados ou delinquentes dentro das relações sociais estabelecidas".

Nessa perspectiva, as crianças e os adolescentes, em condições de precarização, vulnerabilidade e risco social, não se encontram nessa situação por ato de vontade pessoal. E, caso não adiram passivamente às condições sociais, culturais e econômicas, que lhes foram compulsoriamente legadas na singularidade de suas existências, estariam tão somente se dispondo ao mundo como ação divergente, advindo daí a necessidade de compreender suas vozes como táticas empreendidas frente às estratégias acionadas no contexto mais amplo da cultura e das relações sociais.

Michel de Certeau (2012) nos esclarece a distinção entre "estratégias" e "táticas". "[...] Chamo de estratégia o cálculo (ou manipulação) das relações de forças que se torna possivel a partir do momento em que um sujeito de querer e poder (uma empresa, um exército, uma cidade, uma instituição científica) pode ser isolada (CERTEAU, 2012, p. 93)". As táticas são pelo autor compreendidas como os movi- mentos dos "dominados", cuja posição estabelece-se pela espreita das ocasiões para agir, nas palavras do autor: "[...] a tática é a arte do fraco" (CERTEAU, 2012, p. 95).

$\mathrm{Na}$ realidade concreta das medidas protetivas de abrigo, na qual o estudo mais amplo foi realizado, foi possivel compreender as principais táticas engendradas pelas crianças e adolescentes como resistência às sanções institucionais a eles impostas. Nesse contexto, dentre outras táticas, emergem destacadamente os fenômenos da "bagunça" e da "evasão". Concluímos que, nesse contexto, o termo bagunça, ao generalizar ações coletivas ou individuais indisciplinares, ocultaria intencionalidades expressivas que se contraporiam ao rigor da ordem disciplinar, dispondo-se, portanto, como esforços de afirmação de liberdade, existência e criatividade. Nessa direção, as práticas de bagunça no cotidiano do abrigo apresentar-se-iam com a função psicossocial de extravasamento/expressão do descontentamento relativamente à ausência de alternativas às imposições da vida institucional; ainda, de modo pontual, como crítica à qualidade do atendimento recebido pelo serviço de acolhimento institucional; e, finalmente, como função relacional de constituição de vínculos interpares.

Nesse contexto, se o fenômeno da bagunça nos abrigos institui-se como tática de resistência das crianças e adolescentes que neles permanecem, a evasão, por sua vez, corresponderia à resistência daqueles que partem, temporariamente ou não. Fenômeno que mobiliza todos os integrantes da comunidade de acolhimento, a tática da evasão emerge como tema complexo, carecendo de um aprofundamento compreensivo tanto na dimensão dos fatores pontuais que a motivam - ociosidade na ambiência abrigacional e consumo de drogas fora dela -, quanto na dimensão mais ampla do direito dos abrigados à liberdade de 
locomoção, arbitrariamente restrita pelo disciplinamento interno do acolhimento institucional.

Sendo essas duas táticas exemplares dos modos pelos quais as crianças e os adolescentes resistem à condição de tutelados do Estado, vasculhamos, dois anos após a produção dos rastros biográficos audiovisuais por eles produzidos no contexto do estudo doutoral referendado, os fatores por eles eventualmente configurados em suas narrativas audiovisuais acerca das dificuldades de aprendizagem que vivenciavam na escola. A propósito, por "rastros biográficos", compreendemos com Pineau e Le Grand (2012, p. 24), os documentos e objetos que dão testemunhos das passagens da vida pelo tempo, constituídos, segundo os autores, a partir de "práticas de rastros", a exemplo de fotografias e também das formas audiovisuais de registro do homem em ação, atuação e interação no meio ambiente natural e social.

Como subsídio para focalizar as dificuldades de aprendizagem das crianças e adolescentes abrigados, recorremos às analises que faz Mantoan (2015) do momento socioeducacional contemporâneo, frente à mudança paradigmática em curso entre o modelo persistente da exclusão e o que emerge pela via da inclusão educacional. Nesse contexto de transição, a autora constata que, se a escola se democratizou, abrindo-se a novos grupos sociais, não o fez em relação aos conhecimentos por eles aportados às salas de aula, tolhendo a possibilidade de diálogo entre diferentes lugares epistemológicos.

[...] a escola não pode continuar ignorando o que acontece ao seu redor, nem anulando e marginalizando as diferenças nos processos pelos quais forma e instrui os alunos. E muito menos desconhecer que aprender é ser capaz de dar significado a objetos, fatos, fenômenos, à vida. Expressar, dos mais variados modos, o que sabemos implica representar o mundo com base em nossas origens, em nossos valores e sentimentos. (MANTOAN, 2015, p. 22)

Tendo se desenvolvido historicamente na tradição excludente, a escola conservadora resiste à extinção das categorizações e oposições dicotômicas, tais como igual versus diferente e normal versus deficiente. Relativamente ao segmento infantil e adolescente que se encontra sob medida protetiva de abrigo, Fávero, Vitale e Baptista (2008) nos dizem que necessitamos romper com as representações que nos levam à percepção desses indivíduos como integrantes de uma população em situação de desvio social e, como tal, a materialização dos problemas implicados à pobreza, violência, delinquência e drogadição, sendo qualificados de "dificeis" em razão de seus comportamentos.

De que forma as crianças e os adolescentes abrigados explicitam as dificuldades que lhes obstaculizam a formação escolar? Em nossa abordagem, ao acionar a noção de "educação inclusiva", contrapomo-nos à persistente exclusão educacional das pessoas que não correspondem aos espectros ditos normais, historicamente justificada pelo manto da incapacidade daqueles, cujas limitações, sejam elas físicas, mentais ou socioculturais, demandam medidas de acesso ao direito inalienável de todos à educação. $\mathrm{Na}$ indignação de Mantoan (2015, p. 15):

Reluto em admitir certas medidas adotadas pela escola para reagir à diferença de todos nós. De fato, elas existem, persistem, insistem em se manter, apesar de todo o esforço despendido para se demonstrar que as pessoas são singulares, que estão sempre se diferenciando, interna e externamente, e, portanto, não cabem, nem caberão, em categorizações, medidas, padrões.

Assim, em consonância com os pressupostos que atuam para a consolidação do paradigma da educação inclusiva, cujos pilares emergem das interfaces, conexões e encon- 
tros entre os saberes disciplinares e aqueles oriundos da escuta à subjetividade humana, buscamos, em colaboração com os adolescentes participantes deste estudo, contribuir de modo mais amplo para a construção de uma cultura de paz, e, especificamente, compreender as possibilidades de vivenciarmos formas solidárias e plurais de convivência inclusiva, em contextos escolares e na sociedade mais ampla.

\section{Aspectos metodológicos da pesquisa de campo}

Tendo sido inteiramente gravado, o material produzido no decurso dos três ciclos subsequentes de iniciação à linguagem audiovisual - produção de videobiografias e debruce reflexivo sobre tais narrativas audiovisuais - é originariamente submetido à análise, tendo, dentre outros objetivos, a compreensão das potencialidades da videobiografia, frente às possibilidades reflexivas do posicionamento do autor da videobiografia diante do ator da narrativa videobiográfica - sendo ambos uma mesma pessoa civil - procedimento que possibilitou, no caso do estudo com os adolescentes, o estranhamento desses indivíduos frente à própria imagem tecnologicamente reproduzida, fenômeno que carece de posterior aprofundamento.

Segundo Pires (2000), os relatos das pessoas sobre as suas experiências com o vídeo e com as câmaras, em geral, giram comumente no entorno da sensação de estranhamento, ao verem a própria imagem reproduzida, provocando novas formas de percepção em relação a si mesmos. Nas palavras da autora:

A experiência da mediação da imagem técnica proporciona outra visibilidade ao sujeito em relação a si mesmo, desencadeando, paradoxalmente, o sentimento de estranhamento daquilo que the é familiar: a sua própria imagem. Ele percebe que há algo não reconhecivel em rela- ção a si próprio, podendo, posteriormente, incorporar essa nova imagem, assumindo-a como familiar. Nesse momento, vivencia-se uma experiência de transformação da consciência de si. (PIRES, 2010, p. 281).

A experiência interdisciplinar envolvendo videografia e formação pelas histórias de vida, na perspectiva da educação inclusiva, conduz à "Pedagogia Audiovisual", conforme a discute Wohlgemuth (2005), qual seja, uma metodologia que relaciona comunicação audiovisual, cultura popular e saber científico em prol da construção de novos conhecimentos sobre a capacitação de homens e mulheres dos setores populares. Segundo o autor (WOHLGEMU$\mathrm{TH}, 2005$, p. 10), “na seleção dos instrumentos utilizados no estabelecimento de sistemas de comunicação para a aprendizagem, o peso maior recai sobre os audiovisuais, porque permitem superar as barreiras do analfabetismo".

No contexto de produção de videobiografias dos adolescentes, a utilização do vídeo se impôs, ainda, pelo atributo da exibição imediata das imagens produzidas. Nas palavras de Machado (1997, p. 67), “só o vídeo pode restituir o presente como presença de fato, pois nele a exibição da imagem pode se dar de forma simultânea com a sua própria enunciação". Tais condições de expressividade e registro íntimo, em que o sujeito contemporâneo se torna produtor e espectador das próprias mensagens, apontam para a necessidade de discutir novas funções e finalidades do vídeo, dentre elas, a de instrumento de grafia e reflexão sobre si, subvertendo a tradicional posição da tecnologia audiovisual como meio de extensão do homem, ao posicioná-la como meio de inflexão do homem sobre si.

Decorrente desses diálogos teórico-metodológicos advém ainda a percepção de que a articulação interdisciplinar entre os preceitos teórico-metodológicos das histórias de vida em formação e os do método fílmico possi- 
bilitaria a criação de um espaço pelo qual o homem, em qualquer fase da vida, ao ser posto sob a grafia audiovisual, poderá investir em processos de reflexão sobre si, a partir dos mais diferentes registros de suas vivências. Nessa direção, as noções de "auto-mise-en-scène" e "comportamentos profílmicos", conforme as discutem Comolli (2008), possibilitam, em termos de auto-mise-en-scène, a análise da maneira pela qual o personagem real escolhe apresentar suas ações e atividades corporais, materiais e rituais, frente às câmaras, sendo o conjunto dessas ações e atividades considerado um comportamento profilmico.

Nessa perspectiva, Comolli (2008) retoma a noção de auto-mise-en-scène, no contexto da produção de documentários, identificando nela duas dimensões. Na primeira, haveria a forma como inconscientemente o personagem representa a sua realidade social. Na segunda, a maneira pela qual o sujeito, consciente e intencionalmente, se apresenta frente às câmaras, propondo sua própria mise-en-scène. Nas palavras da autora:

Hoje o problema do documentário não é colocar em cena aqueles que filmamos, mas deixar aparecer a mise-en-scène deles. A mise-enscène é um fato compartilhado, uma relação [...] Aqueles que filmam tem como tarefa acolher a mise-en-scène que aqueles que estão sendo filmados regulam, mais ou menos conscientes disso, e as dramaturgias necessárias àquilo que dizem - que eles são, afinal de contas, capazes de dar e desejosos de fazer sentir. (COMOLLI, 2008, p. 60)

Na perspectiva de nossa abordagem do dispositivo videobiográfico, a auto-mise-en-scène inscreve-se como atividade de biografização, a partir das qual, a depender dos objetivos de análise, contribui tanto para a intepretação das atitudes dos atores ou autores postos em registro, quanto para fazê-los refletir sobre tais atitudes. Nessa perspectiva, a noção de auto-mise-en-scène foi especialmente útil na identificação da intencionalidade das crianças e dos adolescentes, por ocasião da apropriação que eles faziam dos espaços de registro audiovisual como meio de expressão, mas igualmente naquelas atitudes pelas quais eles procuravam corresponder às demandas de registro solicitadas.

Nesse processo, as vozes dos sujeitos que, em processos pendulares de resistência e adesão, construíram o percurso instituinte da videobiografia como um dispositivo de pesquisa-ação-formação, permitiu compor um corpus para a pesquisa, cujo material filmico se constituiu naquilo que Freire e Lourdou (2009, p. 19) consideram ser um "segundo trabalho de campo", uma vez que visioná-lo significa, para além do acesso repetitivo e diferido da reprodução técnica dos participantes do estudo, defrontar-se com camadas de presenças e ausências por vezes imperceptiveis.

o lugar do vídeo nessa categoria de práticas de rastros é intrínseco a seus atributos. No contexto do desenvolvimento das atividades videobiográficas, a adequação da tecnologia audiovisual vídeo impõe-se, em diferenciadas dimensões. Deixando as mais óbvias, relativamente implicadas nas dimensões econômicas - fazer vídeo é menos oneroso que fazer cinema, mesmo que cinema digital, por exemplo - e, nas dimensões de portabilidade - a função vídeo encontra-se em formatos variados, assumindo espaços mínimos e discretos -, importa evidenciar o atributo que o distingue no universo das imagens técnicas.

Segundo Machado (1997), produzido e difundido fora do circuito televisual e mais explorado nos espaços domésticos, o vídeo avança na experimentação da linguagem eletrônica, buscando exprimir as inquietações mais agudas dos homens do nosso tempo. 0 vídeo executa uma função cultural de vanguarda, no sentido produtivo do termo: amplia os horizontes, explora novos caminhos, experi- 
menta novas possibilidades de utilização, reverte a relação de autoridade entre produtor e consumidor de imagens.

\section{Sentidos da exclusão escolar para adolescentes abrigados}

Selecionamos para análise, as experiências escolares de dois adolescentes, Beatriz, de 13 anos, e Luiz, de 17 anos - nomes fictícios - consideradas, nesta abordagem, representativas da percepção de si que têm em geral os adolescentes, ao se reconhecerem sob o estigma de pessoas desacreditadas ou desacreditáveis, o que os leva a um estado interior de perpétua vigilância e receio de como serão recepcionados nos mais distintos ambientes sociais, dentre eles, a escola. Neste espaço em especial, esse tipo de representação de si se inscreve como fator prejudicial à formação de um espírito livre, participativo, integrado e adaptativo, com prejuízo às relações sociais que se thes apresentam tanto junto aos demais colegas de escola quanto a seus educadores.

Beatriz havia sido acolhida no abrigo em razão da negligência, abandono, violência doméstica e drogadição da mãe e do padrasto, ambos viciados em "crack". Ao mencionar a escola, em sua videobiografia, a adolescente traz a mãe para o centro de uma memória dramática, pela qual justifica os próprios hábitos de uso de drogas e os motivos para figurar nas estatísticas de evasão escolar.

Um dia minha mãe foi lá (escola) e disse a todo mundo que eu não prestava. Eu estava sentada na sala. Então, ela, que estava brigada comigo, chegou e disse: - Licença, professora. Agora eu quero falar um negócio. Na frente dos meus amigos, na frente das minhas amigas, abriu a boca e disse: - Você é uma drogada. A partir de hoje, você não é mais minha filha. Então, desde aí, eu não considero ela mais como minha mãe. Foi aí que eu tomei distância (da escola), tomei nojo e comecei a usar droga. Parecia que a minha força era as drogas. (BEATRIZ, 13 anos)
Segundo Goffman (2008), o termo estigma surge inicialmente na Grécia, referido às marcas corporais impostas a pessoas ritualmente excluídas - escravos, traidores e criminosos - a serem evitadas especialmente em lugares públicos. Tempos depois, na era cristã, a interpretação dos sinais corporais que emergiam espontaneamente no corpo das pessoas adquire uma outra dimensão, a de graça divina, e decorrente dela a do distúrbio físico. Atualmente, o termo refere-se mais a desgraças pessoais, classificadas nas mais diversas tipologias, estabelecendo os meios de categorizar as pessoas consideradas normais.

Tendo sido exposta ao estigma da drogadição na ambiência escolar, Beatriz, frente aos insultos da mãe, reage em duas direções simultâneas: a evasão escolar e a intensificação do consumo de drogas. Passando à condição de pessoa desacreditada, em função dos hábitos de drogadição, reage aos sentimentos de vergonha, subtraindo-se do cenário em que seus hábitos e desvios de conduta foram publicamente expostos.

Beatriz, acusada pela mãe de ser, tanto quanto ela, usuária de drogas, percebe ruir a identidade social pela qual é percebida, até então correspondente às expectativas compreendidas como normais pela coletividade escolar. 0 episódio narrado a projeta na condição de pessoa "estragada", uma redução do ser comum e integral como, até então, era por todos considerada. O que ocorre, a partir daí, é a focalização privilegiada de um traço que se impõe, afastando a possibilidade de atenção a outros atributos mais virtuosos que the sejam próprios.

No decurso do debruce reflexivo de Beatriz sobre sua narrativa de vida audiovisual, quando a adolescente já havia sido subtraída da ambiência familiar e do convívio da mãe, a percepção de pessoa desacreditada somase agora à condição de pessoa desacreditável, 
uma adição que se deu quando a adolescente, por estar sob a tutela do Estado por medida protetiva, acredita ser esta condição igualmente portadora de estigma e, por isso, decide pela omissão do fato nas relações que estabelece fora dos limites do abrigo institucional.

Tendo realizado um trabalho de escuta com a adolescente, com a finalidade de realizar o processo de "mediação biográfica", definida por Passeggi (2008) como um conjunto de procedimentos pelos quais se realiza o nível lógico de trabalhar sobre a história de vida narrada, instigamos inicialmente a reflexão sobre a evasão escolar da adolescente. Tal debruce leva a adolescente a explicitar o próprio incômodo com o atraso escolar, estendendo ao mediador biográfico a própria descrença que a tem mantido em situação de analfabetismo.

O senhor me ver assim e pensa que eu não quero aprender a ler porque o senhor ver eu mal lendo uma coisa. Eu acho isso! Ver eu mal lendo um livro. Não lendo coisa alguma, porque não tenho aquele gosto, aquele prazer de prender a ler. Mas quando eu vou assim num canto, aí eu digo: poxa, todo mundo lê! Todo mundo vê um livro, sabe o que tem na capa de um livro, todo mundo sabe pegar um ônibus para ir pra algum canto e eu não sei. (BEATRIZ, 13 anos)

$\mathrm{Na}$ condição de Animador, figura antropológica que, no âmbito da mediação biográfica, é assumida pelo mediador, como forma de amparar o nascedouro das ideias e a ação de ressignificação do outro sobre si, para que ele possa renascer, procuramos desfazer tal descrença, delegando à adolescente tarefas que the restaurassem a confiança em si e nos outros. Nesse sentido, foi-lhe delegada a função de multiplicadora dos conhecimentos audiovisuais aos pares de acolhidos que ingressaram no abrigo após o início da oficina de vídeo e que, de alguma forma, demonstraram interesse em participar daquelas atividades. Dias depois, após tomada essa providência, num outro momento de mediação biográfica, a adolescente sentencia.

Eu agora botei na minha cabeça um negócio, que quando a pessoa quer uma coisa, a pessoa se esforça pra ter. E aprender também. Então, eu disse o que? Quero aprender a ler, vai começar as aulas, vou aprender a ler, vou paras aulas, vou crescer na vida e eu, um dia, quem disse que eu não tenho nada pra mostrar, que eu não tenho nada pra prestar, é aí que se engana. Porque, vão ver que eu vou dar a volta por cima. (BEATRIZ, 13 anos)

Quando se dá o reingresso da adolescente na escola, continuávamos as atividades da oficina de vídeo e, simultaneamente, as sessões de debruce sobre as narrativas já produzidas. Enquanto mediador biográfico, instigamos, em uma dessas ocasiões, a reflexão da adolescente sobre a experiência de retorno escolar, perscrutando, nessa ocasião, o constrangimento anteriormente demonstrado por ela relativamente à condição de abrigada. Como resultado, reproduzimos o seguinte diálogo:

Mediador: Perguntaram onde você morava? Beatriz: Não. Mediador: Mas se tivessem perguntado o que você teria respondido? Beatriz: Eu 'dizia' que eu moro numa Casa de Passagem. É assim: quando eu digo, às vezes, os outros me olham com um olhar torto. Por isso, não é em todo canto que eu vou, que eu digo, assim, na cara. Porque os outros ficam, né, assim, bem impressionados, né? Mas, se tivessem me perguntado, eu 'dizia': Eu moro na Casa de Passagem III e, um dia, quando eu sair de lá, vou sair de cabeça erguida. (BEATRIZ, 13 anos)

Luiz, 17 anos. Após dois meses de desembarque no abrigo, nada se sabia de sua origem. 0 adolescente recusava-se a fornecer dados sobre sua história de vida e, por isso, os conselheiros tutelares locais e de outras cidades foram acionados, com o intuito de descobrir eventuais informações de seus familiares. As informações sobre Luiz somente chegaram um mês depois que havíamos iniciado a oficina de 
vídeo. Era natural de uma pequena cidade do interior de Pernambuco e havia fugido de casa, sem que seus familiares sequer suspeitassem o seu paradeiro. Essas informações iniciais nos foram transmitidas pelos educadores sociais.

No contexto da abordagem videobiográfica, Luiz era uma grande interrogação e, também, um desafio. Sendo um dos integrantes mais assíduos e participativos da oficina de vídeo, ele, se até então não havia revelado a sua história para os educadores sociais, como iria fazê-lo no âmbito daquele projeto? Posteriormente, fora do circuito dos registros audiovisuais nos foi revelado que o adolescente havia fugido de casa após ser desacreditado pela mãe, quando finalmente havia criado coragem para revelar os abusos sexuais que havia sofrido entre os cinco e doze anos, de um dos parentes próximos da família.

Essa informação assumiu o devido sentido no decurso das análises da produção videobiográfica do adolescente, quando ele menciona as dificuldades de aprendizagem vivenciadas na escola.

Eu estava na escola, assim, sentado, sabe? Sentava na mesa da escola, nem conseguia se concentrar direito, ficava nervoso, levantava, fugia, ia assim. Começava a pensar nos problemas, coisas da vida. E também sobre o negócio [...] Sobre o negócio da minha mãe que eu falei pro senhor e tal. Começava a pensar naquilo, aí já ficava nervoso, já pensava coisas mal e tal, já ficava naquilo, aí já fugia, já quebrava lápis, rasgava caderno, saia da sala, esses negócios assim. Na maioria das vezes, eu só ia pra bagunçar mesmo, porque muitos problemas, muito negócio na cabeça. (LUIZ, 17 anos)

A evocação das memórias escolares do adolescente, pautadas pela indisciplina, remete às nossas próprias percepções estereotipadas da indisciplina dos nossos educandos. A adesão a tais preconcepções certamente nos leva a caminhar na contramão dos princípios de uma pedagogia que nos orienta a estar con- tinuamente atentos a quão pouco sabemos do outro, advertindo-nos para o dever de estarmos continuamente problematizando a dramaticidade que nos desafia a pensar a realidade humana e a compreender os sentidos ocultos que vêm da barbárie pela qual, sobretudo, nossas crianças e adolescentes, são tratadas.

Foi um tempo ruim, sabe? Quando eu era moleque, muito moleque, eu pensava demais nos problemas. Tanto é que aconteceu uma parada comigo que foi muito triste na minha vida. $\mathrm{E}$ então eu pensava muito naquilo. Ficava muito nervoso. E não dava vontade de estudar não. Mas, depois, quando eu fiquei mais maduro assim um pouquinho da cabeça, mais grandinho, eu já começava a controlar mais. Já não pensar mais naquilo, sabe, e se concentrar mais ali. Aí foi quando eu fui aprendendo a ler mais. E também a professora me ajudou, sabe? A professora da quarta série era mais legal, conversava mais. (LUIZ, 17 anos)

No caso de Luiz, a escuta sensivel que the foi dedicada, em algum momento de sua vida escolar, por uma de suas professoras, é mantida no âmbito de uma lembrança reconhecida e arquivada pela diferença que fez em sua trajetória de formação. Daí que, por entre a contínua recorrência ao episódio que, repetidamente falado, pouco ou nada o adolescente revela, se abre um espaço de gratidão, forjado pela sabedoria do outro que um dia se propôs a ir ao encontro dele, em disponibilidade dialógica.

Colocando-me igualmente disponivel para quaisquer iniciativas do adolescente em dialogar sobre suas aflições, evidentemente que nos limites de nossa participação formativa, conseguimos, aos poucos, fazê-lo participar integralmente das fases de produção videobiográfica e posterior reflexão sobre a narrativa por ele configurada.

Procuro não pensar mais nisso, sabe? Assim, na maioria das vezes vem na lembrança, mas eu procuro não ficar com aquilo na mente, sabe? 
Tentar tirar da minha mente, botar alguma coisa, conversar, fazer outras coisas, para tirar aquilo da mente. Agora, assim, eu já grandão, eu procuro me distrair, não deixar vir àquela lembrança na mente. Cara, assim, a pessoa nunca esquece, mas a pessoa não procura estar com ela na mente direto, entende? Sempre procura esquecer. Apesar que não esquece, mas sempre tenta acalmar a situação. (LUIZ, 17 anos)

Solitário, diante de uma memória com a qual ainda luta continuamente, o adolescente, aos poucos, vê-se forçosamente a aprender modos de administrar as próprias inquietações e angústias. E agora, ocasional e estrategicamente, diz ter forjado modos para afastar tais lembranças da memória, sempre que a situação the exige o redirecionamento disciplinar para outras focalizações. Trata-se, na concepção dele, de um processo de amadurecimento que, de modo significativo, evoca a memória de um encontro com o outro que, um dia, pela via da escuta atenta, se fez mediação de seu ingresso no mundo da cultura escrita pela via da alfabetização.

\section{Considerações sempre parciais}

Partindo dos trechos pelos quais os adolescentes abrigados explicitaram, em suas produções videobiográficas, aspectos para eles significativos de suas experiências escolares, selecionamos as narrativas audiovisuais de dois desses autores videobiográficos, assim destacadas pela relevância que sugere o exercício de uma escuta sensivel das múltiplas formas pelas quais nossos educandos nos expõem a singularidade de suas histórias de vida e, aqui, destacadamente, seus percursos de formação.

Nas duas situações, pensamos ficar demonstrada a compreensão de que, quaisquer que sejam as proposições educativas, elas devem estar enraizadas na vida e na cultura dos indivíduos em formação, com atenção especial à variedade de manifestações de inquietude, afronta, descaso, ironia, indisciplina, dentre outros comportamentos, a partir dos quais os nossos educandos, seja em nível de formação formal ou não formal, desafiam as noções de certo e errado, de bem e mal.

Nesse sentido, assumimos a imprescindibilidade do exercício de uma "escuta sensivel", definida por Barbier (2007, p. 94) como o "saber sentir o universo afetivo, imaginário e cognitivo do outro para 'compreender do interior' as atitudes e os comportamentos, o sistema de ideias, de valores, de símbolos e de mitos".

Corroborando com tal premissa, no âmbito de uma atuação em contextos socioeducacionais de abrigo, Rossetti-Ferreira et al (2010) nos dizem que os objetivos de possibilitar a voz e a visibilidade aos dramas das crianças e adolescentes sugerem a necessidade de abertura e flexibilidade às diferentes formas de linguagem e de narrativas das crianças e dos adolescentes nos processos conversacionais nesses tempos e espaços.

Em outras palavras, o que se quer dizer é que durante a conversa com as crianças é preciso 'viajar' com elas para vários lugares e por meio de diferentes veículos, como músicas, filmes, histórias, contos infantis, desenhos, brinquedos, palavras..., deixando que elas nos guiem. Por isso, um toque de poesia, de inspiração, de ludicidade é necessário nesses momentos. (ROSSETTI-FERREIRA et al, 2010, p. 64)

Tendo por objetivo pensar meios de acompanhar as crianças e os adolescentes em seus processos de formação escolar efetivamente inclusiva, com atenção especial àqueles que vivenciam experiências de fracasso e evasão, percebemos, a partir das experiências analisadas, a relevância da realização de uma escuta atenta às demandas singulares e subjetivas de nossos educandos. Nessa perspectiva, Arroyo (2011, p. 15) nos orienta que, "quando miramos e escutamos as trajetórias humanas e temporais dos educandos e educandas 
outras imagens se revelam". Para o autor, as imagens oriundas dessas oitivas, sem serem romanceadas ou satanizadas, emergem "reais, chocantes, multifacetadas de fracassos, de contravalores, de sombras, mas também de valores, de luzes e de resistências" (ARROYO, 2011, p. 15).

Ao contribuir para a visibilização dessas realidades, pensamos estar subsidiando a produção de um conhecimento educacional e escolar de interesse do movimento de educação inclusiva em curso, uma vez que as práticas de exclusão que se materializam nos tempos e espaços da formação escolar foram aqui abordadas, privilegiadamente, a partir da percepção daqueles que se constituem os próprios objetos deste tipo de discriminação.

Na obra "Pedagogia Social de Rua", de Maria Stela Graciane, Gadotti (2009, p. 14), em prefácio, nos explica que as crianças e adoles-

\section{Referências}

ARROYO, Miguel. Imagens quebradas. Trajetórias e tempos de alunos e mestres. Petrópolis, RJ: Vozes, 2011.

BARBIER, René. A pesquisa-ação. Tradução de Lucie Didio. Brasília, DF: Líber Livro Editora, 2007.

BRASIL. Lei. 8.069, de 13 de julho de 1990. Estatuto da Criança e do Adolescente. Brasília, DF, 1990.

CERTEAU, Michel de. A invenção do cotidiano. Artes de fazer. 18. ed. Tradução de Ephraim Ferreira Alves. Petrópolis, RJ: Vozes, 2012.

COMOLLI, Jean-Louis. Ver e poder: a inocência perdida: cinema, televisão, ficção, documentário. Tradução de Augustin de Tugny, Oswaldo Teixeira e Ruben Caixeta. Belo Horizonte: Editora da UFMG, 2008.

ELIAS, Norbert; SCOTSON, John. L. Os estabelecidos e os outsiders: sociologia das relações de poder a partir de uma comunidade. Tradução de Vera Ribeiro. Tradução do posfácio à edição alemã de Pedro Süssekind. Rio de Janeiro: Jorge Zahar Editor, 2000. centes com experiências e cultura de rualização - caso da maioria da população infantil e adolescente abrigada - não gostam de estudar em escolas burocráticas, insensiveis e que os humilham. "É outra a escola que precisamos construir para elas", diz o autor. Que escola é essa? Evidentemente não existem modelos previamente sistematizados e replicáveis que deem resposta a esta questão.

Pressupomos, no entanto, que as iniciativas que se orientam para a construção de uma escola fundamentalmente democrática e inclusiva devem estar considerando a singularidade e a subjetividade das populações que acolhe, cuja compreensão demanda por uma abordagem multirreferencial, compativel com as complexidades não redutiveis a perspectivas disciplinares, por serem, estas, insuficientes a uma visão global, integrativa e interacionista da questão.

FÁVERO, Eunice Teresinha; VITALE, Maria Amália Faller; BAPTISTA, Myrian Veras (Orgs.). Famílias de crianças e adolescentes abrigadas: quem são, como vivem, o que pensam, o que desejam. São Paulo: Paulus, 2008.

FREIRE, Paulo. Pedagogia da indignação. São Paulo: Editora UNESP, 2000.

FREIRE, Marcius; LOURDOU, Philippe. Descrever o visível. Cinema documentário e antropologia filmica. São Paulo: Estação Liberdade, 2009.

GADOTTI, Moacir. Prefácio. Pedagogia dos Direitos e Pedagogia Social de Rua. In: GRACIANI, Maria Stela S. Pedagogia social de rua. São Paulo: Cortez, 2009. p. 11-17

GOFFMAN, Erving. Estigma. Notas sobre a manipulação da identidade deteriorada. 4. ed. Tradução de Márcia Bandeira de Mello Leite Nunes. Rio de Janeiro: LTC, 2008.

MACHADO, Arlindo. A arte do vídeo. São Paulo: Brasiliense, 1997. 
MANTOAN, Maria Tereza Eglér. Inclusão escolar. 0 que é? Por quê? Como fazer? São Paulo: Summus, 2015.

NÓVOA, António. Prefácio. In: JOSSO, Marie-Christine. Experiências de vida e formação. Natal: EDUFRN; São Paulo: Paulus, 2010. p. 18-25.

PASSEGGI, Maria da Conceição. Mediação biográfica: figuras antropológicas do narrador e do formador. In: PASSEGGI, Maria da Conceição; BARBOSA, Tatyana Mabel Nobre. Memórias, memoriais: pesquisa e formação docente. Natal: EDUFRN; São Paulo: Paulus, 2008. p. 43-59.

PINEAU, Gaston; LE GRAND, Jean Louis. As histórias de vida. Tradução de Carlos Eduardo Galvão Braga e Maria da Conceição Passeggi. Natal: EDUFRN; São Paulo: Paulus, 2012.

PIRES, Eloíza Gurgel. A experiência audiovisual nos espaços educativos: possiveis intersecções entre educação e comunicação. Educação e Pesquisa, São Paulo, v. 36, n. 1. p. 281-295, jan./abr. 2010.
Rossetti-Ferreira et al. A delicada arte da conversa e da escuta. In: BERNARDI, Dayse C.F. (Org.). Cada caso é um caso. Estudos de caso/Projetos de atendimento. São Paulo: Associação Fazendo História: NECA - Associação dos Pesquisadores de Núcleos de Estudos e Pesquisas sobre a Criança e Adolescente, 2010. p. 61-73

SEMURB - Secretaria Municipal de Meio Ambiente e Urbanismo Conheça melhor o seu bairro. Capim Macio. RN, 2008.

SOUZA NETO, João Clemente. Pedagogia social e as políticas sociais no Brasil. In: SOUZA NETO, João Clemente et al. (Orgs.). Pedagogia social. São Paulo: Expressão e Arte Editora, 2009. p. 257-271.

TELeVISÃo CÂMARA. Audiência Pública. Natal: RN, 2009. CD-ROOM

WOHLGEMUTH, Julio. Vídeo educativo. Uma pedagogia audiovisual. Brasília, DF: Editora SENAC, 2005.

Recebido em: 03.02.2016

Aprovado em: 05.03.2016

Cristóvão Pereira Souza é Doutor e Mestre em Educação, pela Universidade Federal do Rio Grande do Norte. Graduado em Jornalismo pela Universidade Federal do Rio Grande do Norte. Dedica-se ao estudo da interdisciplinaridade entre Educação Inclusiva e Pedagogia Audiovisual, através do Método (Auto)Biográfico, tendo a condição das crianças e adolescentes em situação de vulnerabilidade e risco como campo de pesquisa-ação-formação. E-mail: cristovaopereirasouza@gmail.com

Rua Aristides Porpino Filho, no 290 - Ponta Negra -Natal - RN, CEP: 59090.720. Tel. (084) 98816-0157

Maria da Conceição Passeggi é Doutora em Linguística, pela Université Paul Valéry (França). Pesquisadora de produtividade do CNPq-Pq2. Professora Titular, permanente, do Programa de Pós-Graduação em Educação da Universidade Federal do Rio Grande do Norte. Líder do Grupo Interdisciplinar de Pesquisa, Formação, Auto.Biografia, Representações e Subjetividades (GRIFARS-UFRN-CNPq). Presidente da Associação Brasileira de Pesquisa (Auto)Biográfica (BIOgraph). E-mail: mariapasseggi@gmail.com

Rua Alameda das Margaridas, 1275, apt. 201. Tirol - Ed. Victor Hugo, CEP 59020-580 - Natal-RN. Tel. (84) 99121-6944 